\title{
CHEWING AND BITE FORCE EFFICIENCY OF INNOVATIVE IMPLANT ASSISTED OVERDENTURES
}

\author{
Amira M. Gomaa*
}

\begin{abstract}
Introduction: Computer-aided technology is an innovative method for fabrication of removable prosthodontics. Thus, more prospective clinical trials are necessary to validate this technology.

Purpose: The purpose of this study was to evaluate the impact of computer-aided design and computer-aided manufacturing (CAD-CAM) milling technique of prepolymerized Poly Ether Ether Ketone (PEEK) and Poly methyl methacrylate (PMMA) implant assisted overdentures on the chewing efficiency and bite force compared to the conventionally fabricated heat cured acrylic resin overdentures.
\end{abstract}

Materials and Methods: Ten completely edentulous patients with persistent complaint of poor retention and stability of their mandibular complete dentures were selected. Each participant received four dental implants in the anterior mandible. Three identical overdentures were constructed for each patient. According to the processing technique and denture base material, the processed overdentures were classified into three groups. Group I: comprised CAD/CAM milled PEEK overdentures. Group II: comprised CAD/CAM milled PMMA overdentures. Group III: comprised conventional heat cured acrylic resin overdentures. Chewing efficiency of all overdenture groups in terms of measuring the unmixed chewing gum fraction was assessed using two-colour mixing ability test. Biting force was also assessed by a bite force transducer. All assessments were carried out three months after overdenture insertion of each type .

Results: Chewing efficiency and biting force increased significantly with the CAD-CAM milled PEEK and CAD-CAM milled PMMA overdentures compared to the conventionally processed heat cured overdentures. However, no statistically significant difference was detected in the chewing efficiency and biting force when PEEK and PMMA overdentures were used.

Conclusions: The CAD-CAM fabricated overdentures provided increased chewing efficiency and better biting force compared to conventionally processed heat cured overdentures.

KEY WORDS: CAD/CAM dentures, PEEK resin, prepolymerized PMMA resin, bite force, chewing efficiency, implant overdenture.

*Assistant Professor, Removable Prosthodontics, Faculty of Dentistry, Mansoura University, Mansoura, Egypt. 


\section{INTRODUCTION}

The primary goal of prosthodontics is to rehabilitate edentulous patient and provide better function, including masticatory performance. The correlation between masticatory performance, general health and the quality of life of the elderly has attracted the concern of many researchers many years ago. ${ }^{(1,2)}$ According to recent epidemiological studies, the decrease in masticatory ability of the elderly is considered a risk factor that may lead to death on the long run. ${ }^{(3,4)}$

Masticatory efficiency and maximum bite force were evidenced to be improved through supporting removable dentures by dental implants. This is probably the result of better stability and retention of the implant overdentures. ${ }^{(5,6)}$ Therefore, it seems advisable to rehabilitate completely edentulous patients with implant-supported and/or retained overdentures in order to enhance denture retention, improve the masticatory efficiency, decrease pain during chewing and allow use of masticatory muscles thus, allowing patients to chew all kinds of food. ${ }^{(7,8)}$

Removable dentures can be fabricated using different processing techniques. However, the most widely used processing technique is the compression molding technique that has been used for decades. Although this technique has many advantages, dentures may undergo distortion during processing ${ }^{(9)}$ This may lead to reduced retention, stability, support and improper occlusal relationships. In turn, this causes adverse effects on the patient's comfort besides the increased chair side time required for denture adjustment. ${ }^{(10)}$

Many denture processing methods have been settled and enhanced over time in a trail to increase the efficiency of the final prostheses. ${ }^{(10,11)}$. Recently, the advance in dental technology, the computeraided design and computer-aided manufacturing (CAD-CAM) dentures have emerged and became a more popular option for fabrication of denture prostheses. ${ }^{(12,13)}$ The use of prepolymerized blocks of polymethyl methacrylate (PMMA), computer software and the 5-axis milling, CAD-CAM dentures have become a rapidly expanding part of the dental market. ${ }^{(14)}$

CAD-CAM dentures were proved to exhibit less distortion during processing, hence, better adaptation to the underlying mucosa ${ }^{(15)}$ and more effective border seal were resulted. Therefore, it was believed that CAD/CAM dentures exhibit better support, allow better clinical retention and reduce the frequency of denture related traumatic soreness. ${ }^{(16,17,18)}$

CAD-CAM technique moreover allows easy fabrication of alternative dentures using the digitized stored patient clinical data without new clinical records. ${ }^{(19)}$ Also, CAD-CAM dentures can be fabricated in two appointments compared to five appointments required for fabrication of the conventional heat cured processed dentures. Thus, saving the time of dentist, technician and patient. $^{(12,13)}$

Poly Ether Ether Ketone (PEEK) is a new dental polymer material recently introduced to the prosthodontic field. Owing to the reported favorable chemical, mechanical, physical and biological properties, it is used nowadays in fixed and removable prostheses construction as an alternative to the commonly used materials. ${ }^{(20)}$ The PEEK material was proved to exhibit no evidence of cytotoxicity, mutagenicity, carcinogenicity or immunogenicity. It also exhibits high resistance to chemical wear. ${ }^{(21)}$ PEEK is produced either by CAD-CAM milling of the blank disks or by wax wasting management process of the granular form. ${ }^{(22)}$

It was proved that PEEK has a unique properties; it has low modulus of elasticity close to that of bone ${ }^{(23)}$. Furthermore, it is a light material ${ }^{(24)}$ with low density $(1.32 \mathrm{~g} / \mathrm{cm} 3)$. $^{(25,26)}$. Also, laboratory steps are simple and the material can be easily prepared within the mouth. Hence, detailed clinical 
assessments of this new material were required and hence, one of the aims of this study was emerged.

The purpose of this study was to assess the impact of CAD/CAM milled PEEK implant assisted overdentures and CAD/CAM milled PMMAimplant assisted overdentures on the masticatory efficiency and bite force compared to the conventionally fabricated heat cured acrylic resin overdentures.

\section{MATERIALS AND METHODS}

\section{Patients' selection}

Ten completely edentulous healthy patients exhibiting flat mandibular ridge and having complaints associated with persistent insufficient retention and stability of their mandibular dentures were carefully chosen from the out-patient clinic of Prosthodontic Department, Faculty of Dentistry, Mansoura University.

All participants were informed about full details of the treatment and the study and were allowed to sign an informed consent. The enrolled patients had normal maxillo-mandibular relationship, sufficient interarch distance, bone quantity class IV-VI according to Cawood and Howell ${ }^{(27)}$ and good bone quality classes 1-3 according to Lekholm and Zarb (28). Mandibular bone width and height in the lateral incisor and canine regions were enough to receive four standard sized implants $14 \mathrm{~mm}$ in length and $3.6 \mathrm{~mm}$ in width.

Patients having diabetes, osteoporosis, immune deficiency or those on radiotherapy in the head and neck region or on anticoagulant therapy were excluded. Smokers were also excluded. Patients with history of Temporomandibular joint dysfunction that may interfere with proper chewing and biting patterns were also excluded.

The treatment protocol of this study was accepted by the ethical committee of the Faculty of Dentistry, Mansoura University.

\section{Surgical and prosthetic procedures}

Prior to implants placement, new complete denture was fabricated and delivered for each participant following the conventional clinical method for complete denture construction. ${ }^{(29)}$

Each participant then received four dental implants $14 \mathrm{~mm}$ in length and $3.6 \mathrm{~mm}$ in width (Dentium, Corea) were surgically installed in the anterior region of the mandibular. Two implants were installed in the lateral incisors and the other two implants were installed in the canine regions bilaterally following the submerged surgical technique and conventional loading protocol. The denture base was relieved over the implants and relined with tissue conditioner. Patients were given postsurgical medications, oral and denture care instructions.

After three months of implant installation, implants were uncovered surgically and healing abutments $3 \mathrm{~mm}$ in height were screwed for two weeks. The denture was relieved over the healing abutments and relined with soft lining material. After two weeks, the soft liner was removed from the denture fitting surface and the attachment abutments (Dentium, Corea) were joined to the implants (Figure 1). Metal housings were placed on the abutments. A secondary impression was registered using elastomeric impression material (Alphasil Perfect Muller-Omicron GmbH \& Co. KG, D-51789 Linder, Germany).

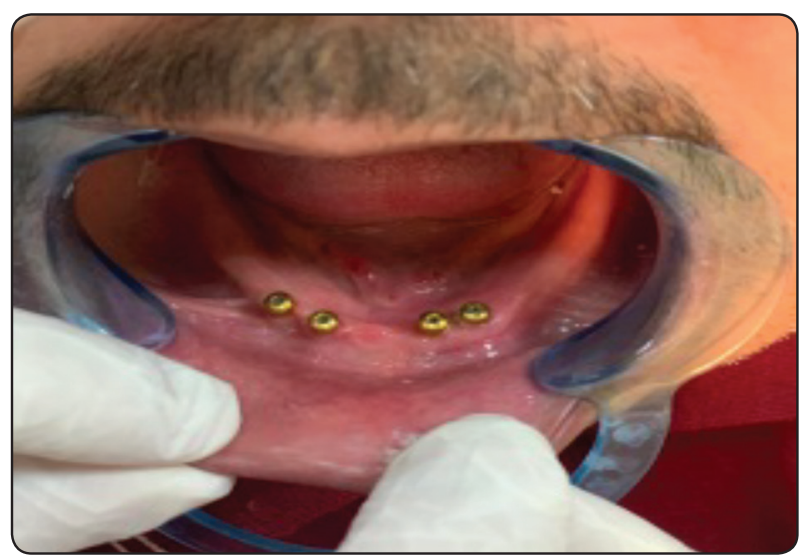

Fig. (1) Attachment abutments connected to the implants. 
Metal housings were removed from the impression and the impression was poured with extra hard stone (kimberlit extra- hard high density die stone-gironaspain). Jaw relations were registered and semianatomical acrylic resin teeth (Ruthinium acrylic teeth, Acry Rock Company, Italy) were arranged and tried in the patient's mouth. The trail denture was processed.

According to the lower overdenture base material and processing technique, the mandibular overdenture prostheses were classified into three equal groups. Group I: comprised overdentures designed using CAD software and manufactured by milling the prepolymerized PEEK resin discs. Group II: comprised overdentures designed using CAD software and manufactured by milling the prepolymerized PMMA resin discs. Group III: comprised overdentures conventionally processed from heat cured acrylic resin.

In Group I, Standard tessellation language (STL) file format were formed by scanning the lower master cast and the lower trial denture using 3D scanner (DOF Swing, Corea) (Figure 2). STL file format was imported into the CAD software (EXO CAD- Dental DB 2.2 Valleta) to start the design process and provide a rapid prototype of the trial denture. STL file of the designed denture base was imported into the milling machine (MILL Box 2018 milling machine: ARUM, 400 Corea) to mill the prepolymerized PEEK discs (Copra Peek rose, Germany) and fabricate the overdenture base

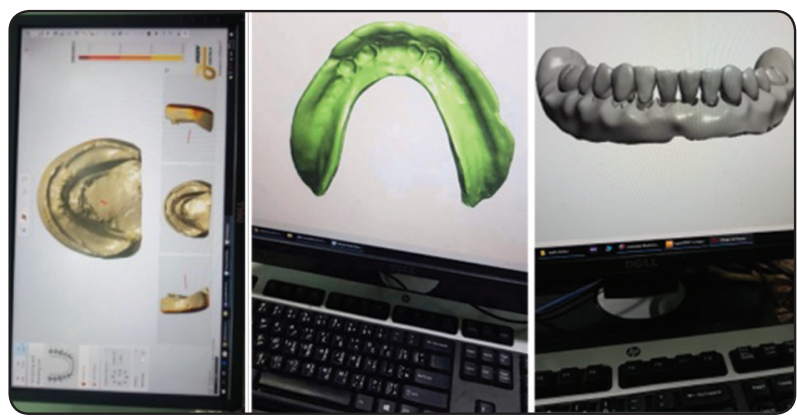

Fig. (2) Virtual master cast, denture base and trial denture created by dental laboratory scanner.

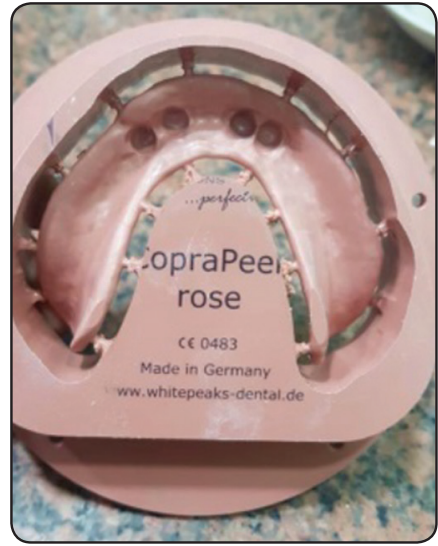

Fig. (3) PEEK resin milled overdenture base

(Figure 3). The milled teeth were bonded into the milled base with a methacrylate-based bonding agent (visio lign bredent UK). The CAD/CAM PEEK overdenture was then finished.

In Group II, The patient's previous STL file was imported into the milling machine (MILL Box 2018 milling machine: ARUM, 400 Corea) to mill the prepolymerized PMMA discs (PMMA Disc, bio HPP, Germany) and fabricate the denture base. Milled teeth were bonded to the overdenture base as in group I. The CAD/CAM PMMA overdenture was then finished.

In Group III, Mandibular overdenture base was fabricated from heat-cured polymethyl methacrylate (Major Prodotti Dentari S.p.A; Italy). The acrylic resin polymer and monomer were thoroughly mixed according to the manufacturer's directions. The heat cured acrylic resin was then packed and polymerized following the conventional technique. (29) Finishing, polishing and occlusal adjustments were then carried out.

\section{Attachment connection}

Direct pick-up procedures were done for attachment connection. A blocking ring was placed over the head of each abutment to block out the area immediately surrounding the abutment and create space around the abutments to prevent contact of 
acrylic resin to the abutments which may transfer excessive moment loads to the implants. The metal housing was placed onto each abutment, leaving the block-out spacer beneath it. Dentures were inserted and tested for any interference with the attachments, then readjusted for maximum planned occlusal contacts in centric and eccentric relations. Self cure acrylic resin was used to pick up the attachment to the fitting surface of the mandibular denture base (Fgure 4 A,B,C).

Prosthetic follow up including occlusal adjustments to ensure even occlusal contact and eliminate occlusal interference that may cause denture instability and mucosal soreness was carried out. Adjustment of denture border extension to avoid pressure and sore spots which may influence the results of this study was also carried out.

All patients were allowed to wear their new dentures for three months to enhance neuromuscular accommodation. Chewing efficiency and maximum bite force assessment were carried out for the first group. Patients were then asked to use group II overdenture dentures for another three months before carrying over out the same assessments. Similar steps were carried out for assessment of group III over dentures.

\section{Evaluation of chewing efficiency}

The three tested groups were evaluated for chewing efficiency three months after denture insertion. Chewing efficiency was assessed using the previously documented two-colour mixing ability test ${ }^{(30)}$ as follow: Two samples were prepared from two colored chewing gums (Trident ${ }^{\circledR}$, Chewing Gum, Mondelez, Egypt); one with spearmint flavor (white colored) and the other with watermelon flavor (red colored). Two strips of a standardized size $(30 \times 18 \times 3 \mathrm{~mm})$ were stuck together manually. Patients were asked to chew the gum samples for 5 , 10, 20, 30 and 50 strokes respectively (Figure 5). Five samples were used for the tests with an interval of rest at least one minute between each to reduce the effect of fatigue.

After chewing, the samples were spat into clear plastic bags. The bags were categorized with corresponding numbers of chewing strokes. All samples were evaluated after flattening to wafers of $1 \mathrm{~mm}$ thickness.

The samples were then digitally scanned by Digital scanner (Binq 5560c Mirascan ${ }^{\circledR}$, Digital scanner, BinQ ${ }^{\circledR}$, USA) from both sides with a resolution 600 dots per inch. The scanned image was copied into an image of fixed size $(1175 \times 925)$ pixels and stored in Adobe Photoshop ${ }^{\circledR}$ format (psd). (Adobe Photoshop 7.0 ME®-Photo Editor Software-Adobe Systems-Incorporated-USA). Then the color range tool (fuzziness 20, 25, 30) and histogram function were used to pick out the unmixed

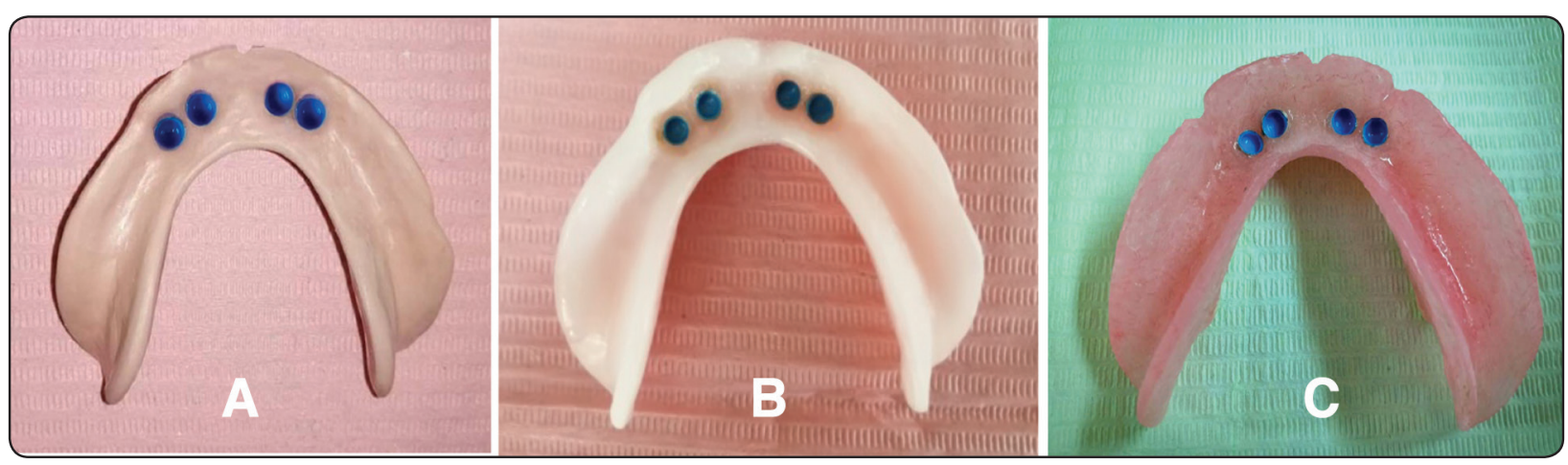

Fig. (4) Mandibular overdentures fitting surface with picked up attachments

A. CAD/CAM milled PEEK. B. CAD/CAM milled PMMA. C. Conventional PMMA. 
white parts of the image. The numbers of selected pixels were documented from the histogram for both sides and means of both figures were calculated. Then the ratio of Unmixed Fraction (UF) was computed using the following formula:

(Pixels white side $a+$ Pixels white side $b$ ) $-2 x$ Pixels of scale $/ 2 \times$ Pixels all.

As a reference scale, a scanned piece of unmixed gum was copied in each image (area of 4779 pixels).

To judge the reproducibility of chewing process, the patients were obtainable to repeat the trials on different days.

This measurement procedures were applied for all assessed dentures.

\section{Evaluation of maximum biting force}

The maximum biting force was recorded using an occlusal force meter device (GM10, Nagano Keiki co, Tokyo, Japan). Patients were seated in an upright position into the dental chair. The force meter fork was inserted between occlusal surfaces of overdenture teeth at the first molar area on both sides of the patient's mouth. Patients were asked to bite as hard as possible on the tip of the dispocap that cover the arm of the forcemeter for three seconds (Figure 6). The highest reading of the three

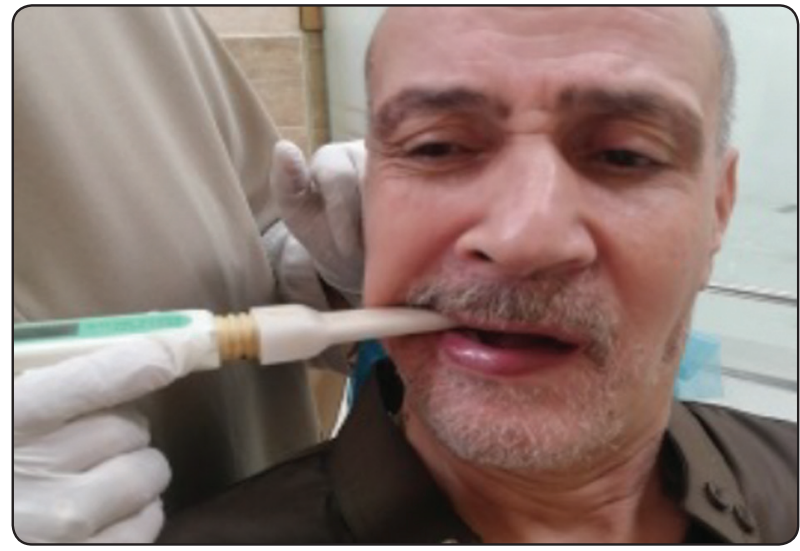

Fig. (6) Patient bite on the tip of the dispocap of the forcemeter with his maximum biting force.

efforts was considered and selected. The mean of the left and right bite force readings were collected and subjected to statistical analysis.

\section{Statistical analysis}

Data of unmixed fraction and maximum biting force measurements were analyzed using SPSS software version 22 (SPSS Inc., Chicago, IL, USA). The collected data for PEEK CAD/CAM, PMMA CAD/CAM and conventionally fabricated PMMA overdentures were compared using oneway ANOVA and repeated ANOVA. P value was significant at 0.05 level.

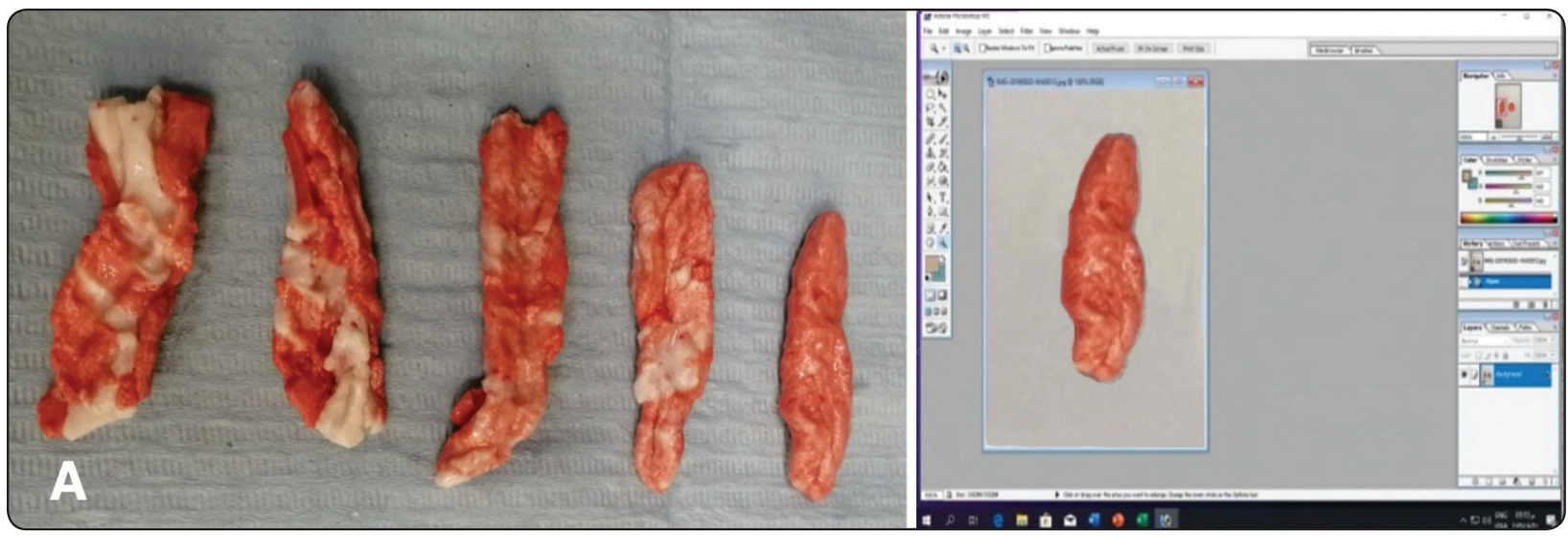

Fig. (5) A, Five chewing gum samples exposed to 5, 10, 20, 30 and 50 chewing strokes respectively. B, Photoshop software identified the non-mixed white pixels by using color range tool (Fuzziness 20, $25,30)$ and histogram tool. 


\section{RESULTS}

Clinically, all patients sharing in the study showed complete compliance to the instruction given regards oral and denture care. All patients expressed complete satisfaction with the dentures and had no complaints concerning retention and functional performance.

Chewing efficiency by CAD-CAM PEEK milled, CAD-CAM PMMA milled resin and conventional heat cured processed implant assisted overdentures.
The means of unmixed fractions (UF) of CADCAM PEEK, CAD-CAM PMMA and conventional heat cured PMMA implant assisted overdentures with different number of chewing strokes are shown in table (1) and figure (7).

The lowest means of unmixed fractions were relevant to the CAD/CAM PEEK fabricated overdentures in all tested strokes and statistically insignificant high means were found relevant to the $\mathrm{CAD} / \mathrm{CAM}$ prepolymeried resin compared to $\mathrm{CAD} /$ CAM PEEK fabricated overdentures in all tested

TABLE (1): Comparison of chewing efficiency (unmixed fractions) between different overdenture prostheses at different number of chewing strokes.

\begin{tabular}{|c|c|c|c|c|c|c|}
\hline Strokes & $\begin{array}{c}5 \text { strokes } \\
\mathrm{X} \pm \mathrm{SD}\end{array}$ & $\begin{array}{c}10 \text { strokes } \\
\mathrm{X} \pm \mathrm{SD}\end{array}$ & $\begin{array}{c}20 \text { strokes } \\
\mathrm{X} \pm \mathrm{SD}\end{array}$ & $\begin{array}{c}30 \text { strokes } \\
\mathrm{X} \pm \mathrm{SD}\end{array}$ & $\begin{array}{c}50 \text { strokes } \\
\mathrm{X} \pm \mathrm{SD}\end{array}$ & $\begin{array}{c}\text { F test } \\
(\mathrm{p} \text { value })\end{array}$ \\
\hline $\begin{array}{c}\text { CAD/CAM } \\
\text { PEEK }\end{array}$ & $0.4093 \pm 0.0212^{\mathrm{a}}$ & $0.3898 \pm 0.0197^{\mathrm{a}}$ & $0.3695 \pm 0.0147^{\mathrm{a}}$ & $0.3515 \pm 0.0183^{\mathrm{a}}$ & $0.3265 \pm 0.0092^{\mathrm{a}}$ & $\begin{array}{c}6.329 \\
(0.001)\end{array}$ \\
\hline $\begin{array}{c}\text { CAD/CAM } \\
\text { PMMA }\end{array}$ & $0.4114 \pm 0.0318^{\mathrm{a}}$ & $0.3909 \pm 0.0175^{\mathrm{a}}$ & $0.3701 \pm 0.0198^{\mathrm{a}}$ & $0.3521 \pm 0.0175^{\mathrm{a}}$ & $0.3285 \pm 0.0081^{\mathrm{b}}$ & $\begin{array}{c}8.639 \\
(0.001)\end{array}$ \\
\hline $\begin{array}{c}\text { Conventional } \\
\text { PMMA }\end{array}$ & $0.4622 \pm 0.0341^{\mathrm{b}}$ & $0.4521 \pm 0.0219^{\mathrm{b}}$ & $0.442 \pm 0.0237^{\mathrm{b}}$ & $0.4386 \pm 0.0238^{\mathrm{b}}$ & $0.4090 \pm 0.0216^{\mathrm{b}}$ & $\begin{array}{c}4.281 \\
(0.01)\end{array}$ \\
\hline $\begin{array}{c}\text { F test } \\
(\mathrm{p} \text { value })\end{array}$ & $\begin{array}{c}5.392 \\
(0.01)\end{array}$ & $\begin{array}{c}6.001 \\
(0.003)\end{array}$ & $\begin{array}{c}7.321 \\
(0.001)\end{array}$ & $\begin{array}{c}8.031 \\
(0.001)\end{array}$ & $\begin{array}{c}10.231 \\
(0.000)\end{array}$ \\
\hline
\end{tabular}

$X:$ Mean $\quad S D:$ Standard deviation

Different letters within the same column indicate a significant difference between means of unmixed fractions of different chewing strokes.

*P value is significant at .05 level.

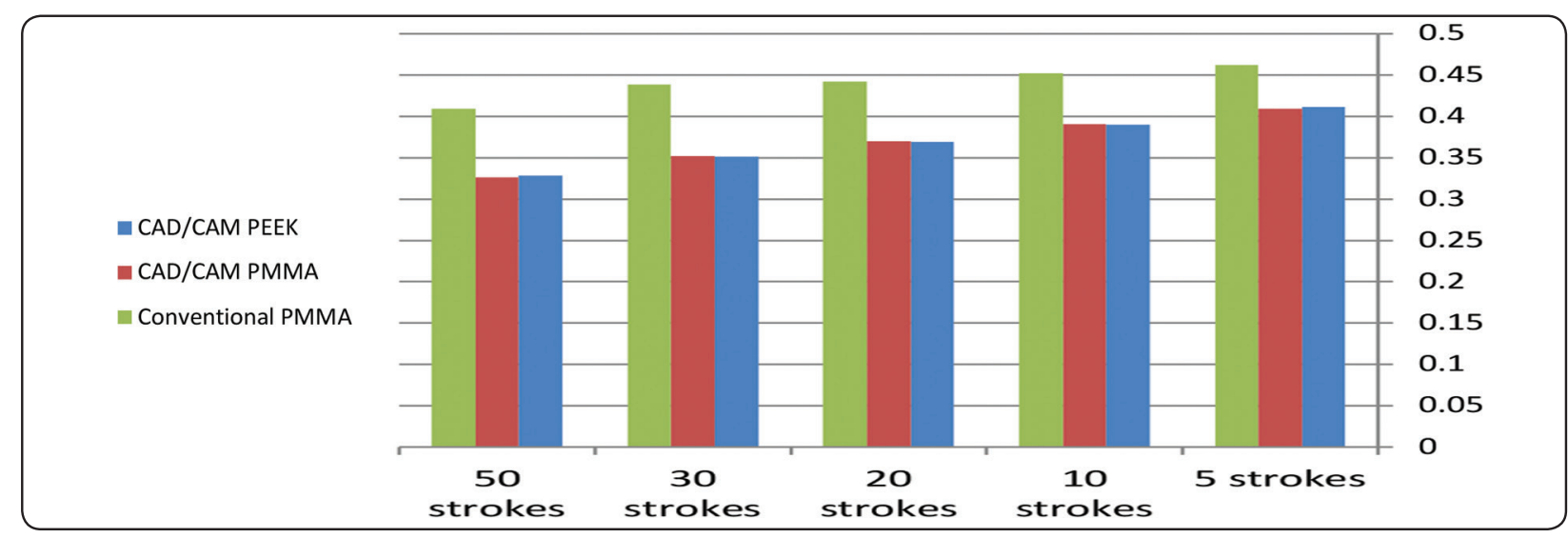

Fig. (7): Histogram revealing the difference in the means of unmixed fractions when PEEK CAD/CAM, PMMA CAD/CAM and conventionally fabricated PMMA overdentures were used. 
strokes. However, the highest means of unmixed gum were obtained when the conventionally processed heat cured resin was used. A statistically high significant difference in the means of unmixed fractions were evident when CAD/CAM overdentures compared to conventionally fabricated overdentures. $(\mathrm{P}<0.005)$ as shown in table $(1)$ and figure (7).

The mean ratio of UF decreased significantly when the number of chewing cycles increased indicating a greater degree of color mixture.

TABLE (2): Descriptive analysis of maximum biting force $(\mathrm{MBF})$ of different overdenture prostheses.

\begin{tabular}{|c|c|c|c|c|}
\hline & $\begin{array}{l}\text { CAD/CAM } \\
\text { PEEK }\end{array}$ & $\begin{array}{c}\text { CAD/CAM } \\
\text { PMMA }\end{array}$ & $\begin{array}{c}\text { Conventional } \\
\text { PMMA }\end{array}$ & $\begin{array}{c}\text { F test } \\
(\mathrm{P} \text { value })\end{array}$ \\
\hline Mean & $187.3^{\mathrm{a}}$ & $186.5^{\mathrm{a}}$ & $163.9^{\mathrm{b}}$ & \multirow{5}{*}{$\begin{array}{c}7.964 \\
(0.001)\end{array}$} \\
\hline Median & 187.2 & 186.5 & 163.5 & \\
\hline $\begin{array}{l}\text { Standard } \\
\text { deviation }\end{array}$ & 3.85 & 2.85 & 3.94 & \\
\hline Minimum & 159 & 156 & 120 & \\
\hline Maximum & 217 & 215 & 231 & \\
\hline
\end{tabular}

Different letters within the same row indicate a significant difference between means of $\mathrm{MBF}$.

*P value is significant at .05 level.

Maximum biting force by CAD-CAM PEEK, CAD-CAM PMMA resin and conventional heat cured processed implant assisted overdentures.

The descriptive analysis of Maximum biting force (MBF) of CAD-CAM PEEK, CAD-CAM PMMA and conventional heat cured PMMA implant assessed overdentures are presented in table (2).

The highest means of MBF were relevant to the CAD/CAM PEEK fabricated overdentures followed by CAD-CAM PMMA while the conventional heat cured PMMA recoded the lowest MBF. A highly statistical significant difference in the means of MBF between the three tested overdentures were evident $(\mathrm{P}<0.005)$ as shown in table $(2)$.

\section{DISCUSSION}

It has been reported that masticatory function of edentulous patients is considerably compromised compared to those with natural dentitions. ${ }^{(31,32)}$ To compensate this impaired masticatory function, edentulous patients are commonly rehabilitated with conventional acrylic complete dentures. Nevertheless, this traditional treatment did not fully satisfy the edentulous patients' needs due to continuous complaints of poor retention and stability, pain or reduced masticatory efficiency. ${ }^{(33)}$ Continuous attempts were carried out to enhance the retention and stability of removable complete denture. Rehabilitation of edentulous patients with implant-retained mandibular overdenture has proved great improvement in patient's satisfaction, comfort, chewing efficiency and bite force. ${ }^{(7,34)}$

Up till now, researchers have investigated the masticatory function with conventional mandibular dentures anchored to dental implants, ${ }^{(7)}$ relining of old conventional denture ${ }^{(35)}$, different implant number, ${ }^{(5)}$ different attachment techniques ${ }^{(36)}$ and implant loading protocol. (37) The present study aimed to assess the presence of changes and/or improvements of the masticatory efficiency and maximum biting force of patients rehabilitated with implant assisted overdentures manufactured by $\mathrm{CAD} / \mathrm{CAM}$ milled technique using the recently introduced materials compared to conventionally processed acrylic implant assisted overdentures.

The most commonly used process for evaluating masticatory performance is a comminution process using sieves. Sieving methods are considered by many authors as gold standard for masticatory efficiency evaluation. To overcome the inconveniences of specialized equipment and the collection of the very small food particles, digital scanning of sieved food particles is proposed by digital software. ${ }^{(38)}$

Recently, the degree of mixing ability was documented as an alternative to sieving method. ${ }^{(39)}$ In this study, the colour mixing ability test using 
two colours of chewing gum was used to assess the masticatory efficiency. The degree of color change indicated the degree of mixing ability. ${ }^{(30,39,40,41)}$

Data provided by following this method are reported to be accurate as no comminuted particles got stuck under dentures or swallowed. ${ }^{(42)}$ Also, the material used is elastic in consistency thus, allowing the use of maximum muscle activity. Chewing gum is mostly obtainable and its chewing properties are recognized to most persons. ${ }^{(40,43)}$

In an attempt to reduce human variables and to standardize the assessed prosthetic appliances study was designed to compare patients with themselves using three identical overdentures for each patient.

The masticatory efficiency and bite force evaluation started three months after denture insertion to allow adequate time for proper neuromuscular adaptation to the prosthesis required for allowing proper functional performance as previously reported. ${ }^{(44)}$

Both male and female were allowed to share in this study, as previous studies evidenced no gender differences in bite force and masticatory performance among complete denture wearers. ${ }^{(45)}$

The significant improvement of masticatory efficiency indicated by the significant decrease of the mean ratio of unmixed friction (UF) and the maximum biting force (MBF) of the CAD-CAM fabricated overdentures could be explained by the previously reported better overdenture adaptation of CAD-CAM fabricated overdentures compared with pack and press fabricated overdentures. ${ }^{(15)}$ Better adaptation is certainly associated with better retention, as well as better function. ${ }^{(18)}$ Thus, patients had the ability to chew comfortably and exert higher force on the examined specimens when CAD/CAM fabricated overdentures were used. ${ }^{(46)}$

The improved adaptation of the CAD/CAM fabricated dentures is probably attributed to the subtractive manufacturing process as the denture bases are milled from fully polymerised acrylic resin pucks, hence, ${ }^{(14)}$ the fabricated prosthesis is not liable to shrinkage or distortion. ${ }^{(47)}$ Therefore, the CAD/CAM fabricated denture exhibited higher compatibility with the master cast surface compared to the conventionally fabricated dentures as previously explained. $(15,16,48)$

The enhanced comminuting ability of food during mastication reported by patients sharing in this study and compared to less effective masticatory function reported in the dental literature by patients wearing conventional complete dentures could be explained by the increased retention and stability of the implant retained mandibular overdentures which probably increase the muscle activity ${ }^{(49)}$ and hence, the better ability to comminute food during mastication. It has been previously reported and documented in the dental literature mandibular implant assisted removable dentures improve the masticatory efficiency to all kinds of food and reduce pain during chewing. ${ }^{(5,8)}$

The low masticatory efficiency and biting force of conventionally processed PMMA overdentures evidenced from the results of this study could be attributed to the commonly evidenced and documented dimensional changes of denture base resin which usually occur during processing as a result of curing shrinkage, internal stress release and expansion which occur due to water absorption. ${ }^{(50)}$

These changes would result in the combination of both areas of the mucosa that are impinged upon and others that are out of contact with the denture resulting in sore spots together with compromised denture stability and retention. ${ }^{(51,52)}$ This decrease in retention and stability and presence of sore spots has adverse consequences on patient's comfort and masticatory function because of required adjustments.

The significant reduction of mean ratio of UF evidenced in this study when the number of chewing cycles increased as indicated by higher degree of color mix is probably due to the increased 
masticatory efficiency of the patients. This result was in agreement with observation of other studies conducted on mandibular overdentures. ${ }^{35,53)}$

\section{CONCLUSION}

Within the limitations of the present study, it can be concluded that restoring the edentulous mandibule with $\mathrm{CAD} / \mathrm{CAM}$ fabricated implant assisted overdenture improves the masticatory efficiency and maximum biting force compared to conventionally fabricated acrylic resin overdenture.

\section{ACKNOWLEDGEMENTS}

Deep thanks and gratitude to Dr. Fatma Awad, Professor of Removable Prosthodontics, Faculty of Dentistry, Ain Shams University, for her continuous and unlimited help. The help of Dr. Ahmed Habib Professor of Removable Prosthodontics, Faculty of Dentistry, Mansoura University in placing the implants in this study is greatly appreciated.

\section{REFERENCES}

1. Kimura Y, Ogawa H, Yoshihara A, Yamaga T, Takiguchi T, Wada T, et al. Evaluation of chewing ability and its relationship with activities of daily living, depression, cognitive status and food intake in the community dwelling elderly. Geriatr Gerontol Int 2013;13:718-25.

2. Okada K, Enoki H, Izawa S, Iguchi A, Kuzuya M. Association between masticatory performance and anthropometric measurements and nutritional status in the elderly. Geriatr Gerontol Int 2010;10:56-63.

3. Tanaka T, Takahashi K, Hirano H, et al. Oral frailty as a risk factor for physical frailty and mortality in community-dwelling elderly. J Gerontol A Biol Sci Med Sci. 2018;73:1661-1667.

4. Nakanishi N, Fukuda H, Takatorige T, Tatara K. Relationship between self-assessed masticatory disability and 9-year mortality in a cohort of community-residing elderly people. J Am Geriatr Soc. 2005;53:54-58.

5. Nogueira TE, Schimmel M, Leles CR. Changes in masticatory performance of edentulous patients treated with single implant mandibular overdentures and conventional complete dentures. J Oral Rehabil. 2019;46:268-273
6. Mesbah R, Khalifa A, Abdelfadel E, El Mekawy N. Masticatory efficiency of complete mandibular overdenture assisted by prefabricated round bar. Egy. Dent. J. 2017; 63: 769-772.

7. Boven GC, Raghoebar GM, Vissink A, Meijer HJ. Improving masticatory performance, bite force, nutritional state and patient's satisfaction with implant overdentures: a systematic review of the literature. J Oral Rehabil. 2015;42:220-33.

8. Marco M, Giuliano B, Luca O. Oral rehabilitation with implant-supported overdenture and a new protocol for bar passivation. Glob. J. Oral Sci. 2016; 2: 10-19.

9. Yeung KC, Chow TW, Clark RK. Temperature and dimensional changes in the two-stage processing technique for complete dentures. J Dent 1995;23: 245-53.

10. Sykora O, Sutow EJ. Posterior palatal seal adaptation: influence of processing technique, palate shape and immersion. J Oral Rehabil 1993;20:19-31.

11. Anderson GC, Schulte JK, Arnold TG. Dimensional stability of injection and conventional processing of denture base acrylic resin. J Prosthet Dent. 1988;60:394-8.

12. Saponaro PC, Yilmaz B, Heshmati RH, McGlumphy EA. Clinical performance of CAD-CAM-fabricated complete dentures: a cross-sectional study. J Prosthet Dent 2016; 116:431-5.

13. Bidra AS, Taylor TD, Agar JR. Computer-aided technology for fabricating complete dentures: systematic review of historical background, current status, and future perspectives. J Prosthet Dent 2013;109:361-6.

14. Goodacre CJ, Garbacea A, Naylor WP, Daher T, Marchack CB, Lowry J. CAD/CAM fabricated complete dentures: concepts and clinical methods of obtaining required morphological data. J Prosthet Dent 2012;107:34-46.

15. Goodacre BJ, Goodacre CJ, Baba NZ, Kattadiyil MT. Comparison of denture base adaptation between CADCAM and conventional fabrication techniques. J Prosthet Dent 2016; 116: 249- 56.

16. Steinmass O, Dumfahrt H, Grunert I, Steinmass PA. CAD/ CAM produces dentures with improved fit. clinical oral investigations 2018; 22:2829-2835.

17. Darvell BW, Clark RK. The physical mechanisms of complete denture retention. Br Dent J 2000;189:248-52.

18. AlHelal, A,. AlRumaih HS, Kattadiyil MT, Baba N, Goodacre CJ. Comparison of retention between maxillary milled and conventional denture bases: A clinical study Prosthet Dent 2017;117:233-238 
19. Goodacre BJ, Goodacre CJ, Baba NZ.Using Intraoral Scanning to Capture Complete Denture Impressions, Tooth Positions, and Centric Relation Records int J Prosthodont 2018;31:377-381.

20. Skirbutis G, Dzingutė A, Masiliūnaitè V, Šulcaitė G, Žilinskas J. PEEK polymer's properties and its use in prosthodontics. A review Stomatologija, Baltic Dental and Maxillofacial Journal 2018; 20: 54-8.

21. Wenz LM, Merritt K, Brown SA, et al. In vitro biocompatibility of polyetheretherketone and polysulfone composites. J Biomed Mater Res. 1990;24: 207-215.

22. Muhsin SA, Hatton PV, Johnson A, Sereno N, Wood DJ. Determination of Poly ether ethe rketone (PEEK) mechanical properties as a denture material Saudi Dental Journal 2019;1-10.

23. Rodriguez F, Cohen C, Ober CK, \& Archer L. Principles of polymer systems 6th Edition. New York: Taylor \& Francis US. 2014.

24. Rabiei A, Sandukas S. Processing and evaluation of bioactive coatings on polymeric implants. J Biomed Mater Res Part A 2013;101:2621-9.

25. Schwitalla AD, Abou-Emara M, Zimmermann T, Spintig T, Beuer F, Lackmann J, \& Müller WD. The applicability of PEEK-based abutment screws. Journal of the mechanical behavior of biomedical materials 2016;63:244-251.

26. Schwitalla AD, Spintig T, Kallage I, \& Müller WD. Flexural behavior of PEEK materials for dental application. Dental Materials 2015;31:1377-1384.

27. Cawood JI, Howell RA. A classification of the edentulous jaws. The International Journal of Oral and Maxillofacial Surgery 1988;17: 232-236.

28. Lekholm, U. \& Zarb, G. Patient selection and preparation. In: Branemark pi, zarb g, albrektsson t, eds. Tissue integrated prosthesis: Osseointegration in clinical dentistry. Chicago. Quintessence Publishing Co. Inc.: 1985;199-209.

29. Zarb G, Bolender C, Eckert S, Jacob R, Fenton A, Mericske-Stern R. Prosthodontic treatment for edentulous patients, 12th edition, 2003; 211-425. St Louis: Mosby.

30. Schimmel M, Christou P, Herrmann F, Muller F. A two colour chewing gum test for masticatory efficiency: Development of different assessment methods. J Oral Rehabil 2007; 34: 671-678.

31. Okamoto N, Morikawa M, Tomioka K, Yanagi M, Amano N, Kurumatani N. Association between tooth loss and the development of mild memory impairment in the elderly: the Fujiwara kyo Study. J Alzheimers Dis. 2015; 44:777-786.

32. Walton JN, MacEntee MI. Choosing or refusing oral implants: a prospective study of edentulous volunteers for a clinical trial. Int J Prosthodont. 2005;18:483-488.

33. Carlsson GE, Omar R. The future of complete dentures in oral rehabilitation. A critical review. J Oral Rehabil 2010; 37:143-56.

34. Elsyad MA, Khairallah AS. Chewing efficiency and maximum bite force with different attachment systems of implant overdentures: a crossover study. Clin Oral Implants Res 2017;28:677-82.

35. Sabrina Maniewicz S, Duvernay E, Srinivasan1 M, Perneger T, Schimmel M, Müller F. Effect of implant supported mandibular overdentures versus reline on masticatory performance and salivary flow rates in very old adults-A randomized clinical trial. Clin Oral Impl Res. 2019;30: 59-67.

36. Toia M, Wennerberg A, Torrisi ,P Farina V, Corrà E, Cecchinato E. Patient satisfaction and clinical outcomes in implant supported overdentures retained by milled bars: Two year follow up. J Oral Rehabil. 2019;1-10.

37. Khalifa AK, Abdel-Khalek EA, El Mekawy Comparing masticatory efficiency of mandibular bar-supported overdentures with different loading protocols. N. Egy. Dent. J. 2018; 64:1159:1167.

38. Eberhard L, Schneider S, Eiffler C, Kappel S, Giannakopoulos NN. Particle size distributions determined by optical scanning and by sieving in the assessment of masticatory performance of complete denture wearers. Clin Oral Investig 2015;19:429-36.

39. Wada, S, Kawate N, Mizuma M. What type of food can older adults masticate?: Evaluation of mastication performance using color changeable chewing gum. Dysphagia 2017;32:636-643.

40. Stjernfeldt PE, Sjögren P, Wårdh I, Boström AM. Systematic review of measurement properties of methods for objectively assessing masticatory performance. Clin Exp Dent Res. 2019;5:76-104.

41. Silva LC, Nogueira TE, Rios LF, Schimmel M, Leles CR. Reliability of a two colour chewing gum test to assess masticatory performance in complete denture wearers. J Oral Rehabil. 2018;45:301-307. 
42. Liedberg B, Owall B. Oral bolus kneading and shaping measured with chewing gum. Dysphagia 1995; 10: 101106.

43. van der Bilt A, Mojet J, Tekamp FA, Abbink JH. Comparing masticatory performance and mixing ability. Journal of Oral Rehabilitation 2010;37:79-84.

44. Giannakopoulos NN, Corteville F, Kappel S, Rammelsberg P, Schindler HJ, Eberhard L. Functional adaptation of the masticatory system to implant-supported mandibular overdentures. Clin. Oral Impl. Res. 2017;28:529-534.

45. Soboleva U, Laurina L, Slaidina A. The masticatory system-an overview. Stomatologija Baltic Dental and Maxillofacial Journal. 2005;7:77-80.

46. Fontijn-Tekamp F, Slagter A, Van Der Bilt A, Van 'T Hof M, Witter D, Kalk W, Jansen J. Biting and chewing in overdentures, full dentures, and natural dentitions. J Dent Res. 2000;79:1519-24.

47. Kattadiyil MT, Jekki R, Goodacre CJ, Baba NZ. Comparison of treatment outcomes in digital and conventional complete removable dental prosthesis fabrications in a predoctoral setting. J Prosthet Dent 2015;114:818-825.
48. Srinivasan M, Cantin Y, Mehl A, Gjengedal H, Müller F, Schimmel M. CAD/CAM milled removable complete dentures: an in vitro evaluation of trueness. Clin Oral Investig 2017;21:2007-19

49. van der Bilt, A., van Kampen, F. M. \& Cune, M. S. Masticatory function with mandibular implant-supported overdentures fitted with different attachment types. Eur J Oral Sci 2006;114: 191-196.

50. Wong DM, Cheng LY, Chow TW, Clark RK. Effect of processing method on the dimensional accuracy and water sorption of acrylic resin dentures. J Prosthet Dent 1999;81:300-4.

51. Seo-Ryeon Lim, Joon-Seok Lee. Three dimensional deformation of dry-stored complete denture base at room temperature J Adv Prosthodont 2016;8:296-303.

52. Allahyari S, Niakan S. Processing techniques of acrylic resin in removable and maxillofacial prosthesis: A review. J Craniomax Res 2018; 5:99-104.

53. Gomaa AM. chewing efficiency with mini-implant supported mandibular overdentures Egy. Dent. J. 2014; 60. 